\title{
Energy Release during the Recrystallization Process and the Recrystallization Texture in Cold Rolled $\mathrm{Cu}$
}

\author{
By Akira Okada*, Haruo Mitsuji** and Hitoshi Nakaé*
}

\begin{abstract}
The variation of the energy release during the recrystallization process and the texture change were investigated by differential calorimetric analysis and X-ray texture measurements of $\mathrm{Cu}$ sheets cold rolled by various rolling procedures. Copper sheets of $2 \mathrm{~mm}$ thick were at first rolled in one direction (primary rolling), then rolled to a final thickness of $0.1 \mathrm{~mm}$ in the transverse direction (secondary rolling). The amount of deformation in the secondary rolling was 9 to $90 \%$ reductions in thickness. On slight secondary reductions less than $20 \%$, the rolling texture changed little and the recrystallization texture showed a well-developed cube texture, whereas, the activation energy for the recrystallization decreased from 74 to $62 \mathrm{kcal} / \mathrm{mol}$. For the specimens secondly rolled by $9 \%$ to $75 \%$, the activation energy had an almost constant value of 62 $\mathrm{kcal} / \mathrm{mol}$. The condition for the "intrinsic" growth of the cube oriented grain would be easily collapsed, then only a slight reduction of secondary rolling affected the growth behavior of the cube grain. The predominance of the cube grain growth presumably originated from the configuration of the boundary regions between the cube component and the matrix in the deformed materials. However, no difference in the recrystallization behavior was found among the specimens by electron microscopy.
\end{abstract}

(Received January 30, 1974)

\section{Introduction}

A great many studies ${ }^{(1)}$ have been reported on the phenomena of recovery, nucleation and grain growth in the recrystallization process of cold worked metals. Most of them have dealt with the mechanism of the grain growth or the crystal geometric relationships between cold worked textures and recrystallization textures. The recrystallization kinetics, such as the change in grain size and recrystallized volume fraction, and the energy release during the recrystallization, were investigated by Johnson and $\mathrm{Mehl}^{(2)}$, Avrami $^{(3)}$, and Burke and Turnbull ${ }^{(4)}$, from the viewpoint of the grain growth process in relation to the rate controlling process.

It may be a most direct method for the study of these phenomena to measure the energy release during recrystallization ${ }^{(5)(6)}$. The stored energy measurements were also carried out in the studies of the work hardening mechanism by Williams ${ }^{(7)}$ for the polycrystalline $\mathrm{Cu}$ and by Steffen et al. ${ }^{(8)}$ and Wolfenden ${ }^{(9)}$ for single crystals of $\mathrm{Cu}$, respectively. More recently, Grewe et al. ${ }^{(10)}$ investigated the effects of the driving force on the recrystallization of polycrystalline aggregates and single crystals of $\mathrm{Cu}$ by the measurements of the growth rate and electrical resistance and by the torsion test. The polycrystalline specimens with any preferred orientation texture have never been used for these measurements, because the grain growth is treated as the uniformly proceeding process. In general, the preferred orientations of polycrystalline aggregates develop corresponding to the deformation modes. Also, this phenomenon is similar to the case of the recrystallization textures formed by the subsequent annealing of them. It will be impossible to avoid com-

* Department of Precision Engineering, Faculty of Engine. ering, Hokkaido University, Sapporo 060, Japan.

** Graduate School, Hokkaido University, Sapporo 060, Japan. Present address: Nippon Kokan Co., Kawasaki 210, Japan. pletely this tendency during the deformation and recrystallization.

From a different standpoint, the present authors have studied the formation process of the cube texture in $\mathrm{Cu}$, which is a representative recrystallization texture of face-centered cubic metals by differential calorimetric analysis of heavily cold-rolled $\mathrm{Cu}$. The various rolling processes were employed for performing secondary rolling in the transverse direction of primary rolling. Even if the same amount of cold rolling reduction was applied to the specimen, the varied amounts of additional secondary rolling reduction result in changes not only in the recrystallization texture but also in the shape of the energy release curves during the recrystallization process. In this experiment, a study of these phenomena, particularly the relation between the energy release curves and the recrystallization texture, was carried out.

\section{Experimental Procedures}

The specimen used was commercially available tough-pitch $\mathrm{Cu}(99.96 \%$ purity) sheet $2 \mathrm{~mm}$ thick,

Table 1

\begin{tabular}{rlc}
\hline No. & $\begin{array}{c}\text { Primary rolling } \\
\text { reduction }(\%)\end{array}$ & $\begin{array}{c}\text { Secondary rolling } \\
\text { reduction }(\%)\end{array}$ \\
\hline 1 & 95 & 0 \\
2 & 94.5 & 9 \\
3 & 93.8 & 20 \\
4 & 90 & 50 \\
5 & 87.5 & 60 \\
6 & 85 & 67 \\
7 & 83.5 & 70 \\
8 & 80 & 75 \\
9 & 67 & 85 \\
10 & 60 & 87.5 \\
11 & 50 & 90 \\
\hline
\end{tabular}

Rolling procedure

$2 \mathrm{~mm}$-Primary roll-Secondary roll- $0.1 \mathrm{~mm}$ Total reduction rate $95 \%$ 
finally annealed at $600^{\circ} \mathrm{C}$ for $1 \mathrm{hr}$, its grain size being about $30 \mu$. This copper sheet was cold rolled to a final thickness of $100 \mu$ (corresponding to a $95 \%$ reduction) by several secondary rolling processes as shown in Table 1.

The samples for differential calorimetric analysis were about $2 \mathrm{~g}$-weight stacks of the cuts of $1 \mathrm{~mm} \times$ $1 \mathrm{~mm}$. The measurement was carried out in $\mathrm{Ar}$ gas (about $10 \mathrm{mmHg}$ ) at a heating rate of $3.2^{\circ} \mathrm{C} / \mathrm{min}$. On the samples heat treated in the same way as in the case of thermal analysis, 100-pole figures were made using 200-reflection of $\mathrm{Co}-\mathrm{K} \alpha$ radiation. Microscopic observations were also made by optical and electron microscopy.

\section{Experimental Results}

\section{Microscopic observation}

The electron microscopic observation of the thin foils, mounted on the heating stage showed the retardation of recrystallization and the reduction in grain size due to the foil thickness. However, in the thicker regions $(\sim 1 \mu)$ where a barely distinguishable image was formed by electron beams of $650 \mathrm{keV}$, the cube oriented grains appeared preferentially. These microstructures resembled those of the specimens, $100 \mu$ thick, which were annealed in the conventional furnace. This probably suggests that the development of the cube grains depends on the condition whether the cube component is contained as a whole in the region where the cube grains grow or not.

The typical microstructure observed in the specimens cold rolled by $95 \%$ and slightly annealed is shown in Photo. 1, where the cube grain is grown from a band-like structure consisting of (110) [112] and (100) [001]. The present authors ${ }^{(11)}$ have previously found a similar region in the $\mathrm{Ni}-50 \% \mathrm{Fe}$ alloy. As shown in Photo. 2, the band-like structures remained even in the specimens cold rolled with secondary rolling to reductions over $60 \%$. On subsequent annealing, fine

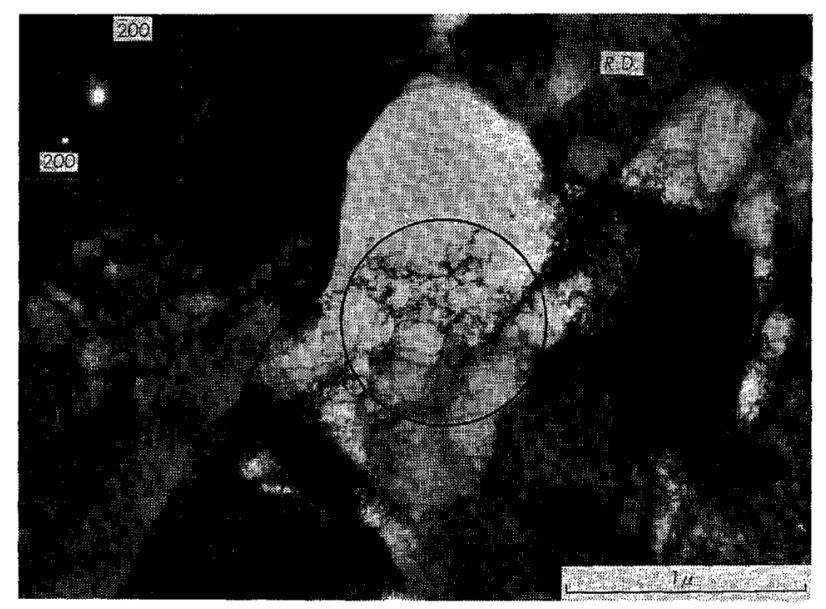

Photo. 1 Transmission electron micrograph of the specimen cold rolled $95 \%$ and annealed at $200^{\circ} \mathrm{C}$ for $10 \mathrm{sec}$. The cube grain is seen growing from the band-like structure consisting of (100)[001] and (110)[112]. recrystallized grains with non-cube orientation were present in the matrix and a few cube oriented grains were also found to grow from the residual band-like structures, as shown in Photo. 3.

The number of the cube grains decreased with increasing secondary rolling reduction, with the reduction in the size of recrystallized grains. The fine recrystallized grains observed in the as-rolled specimens probably resulted from self annealing, because the rolling procedures were performed at room temperature. In the case of rolling without secondary rolling, these fine grains had the cube orientation, whereas the finer grains with non-cube orientations were found in the specimens rolled with secondary reductions. However, no difference in the recrystallization behavior was found in both cases by the microstructure observation.

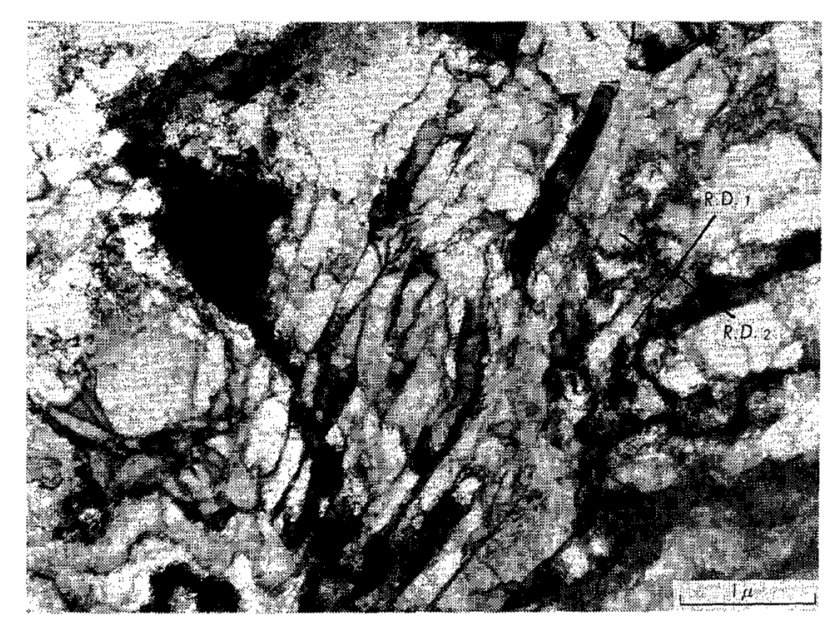

Photo. 2 Cold rolled state of the specimen, primarily rolled $85 \%$ and then secondly rolled $67 \%$. These band-like structures remains in the specimens cold rolled by secondary rolling reduction higher than $60 \%$. In photograph, R.D. 1 and R.D. 2 are primary and secondary rolling directions, respectively.

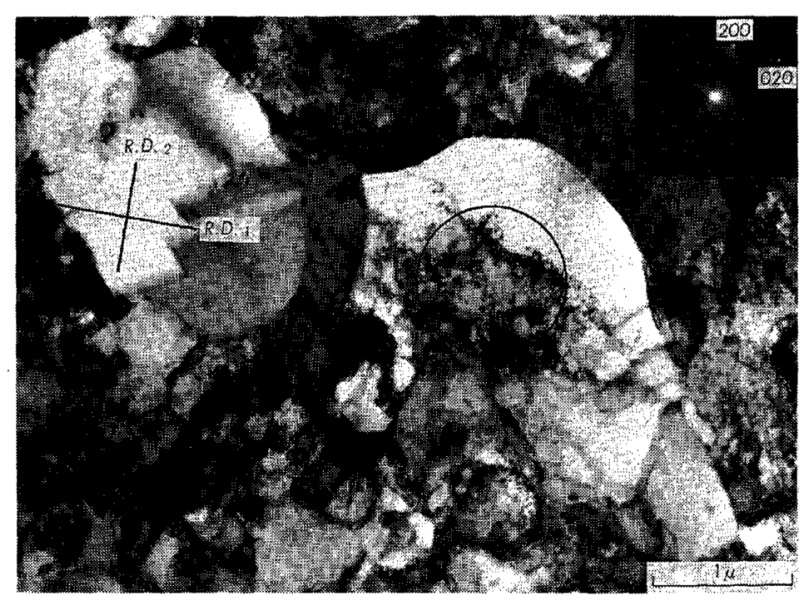

Photo. 3 Transmission electron micrograph showing the cube grain grew from the band-like structure, which remains in the rolled specimen after secondary rolling. Cold rolled $85 \%$ and additional rolling of transversal direction by $67 \%$. Annealed at $200^{\circ} \mathrm{C}$ for 10 sec. 

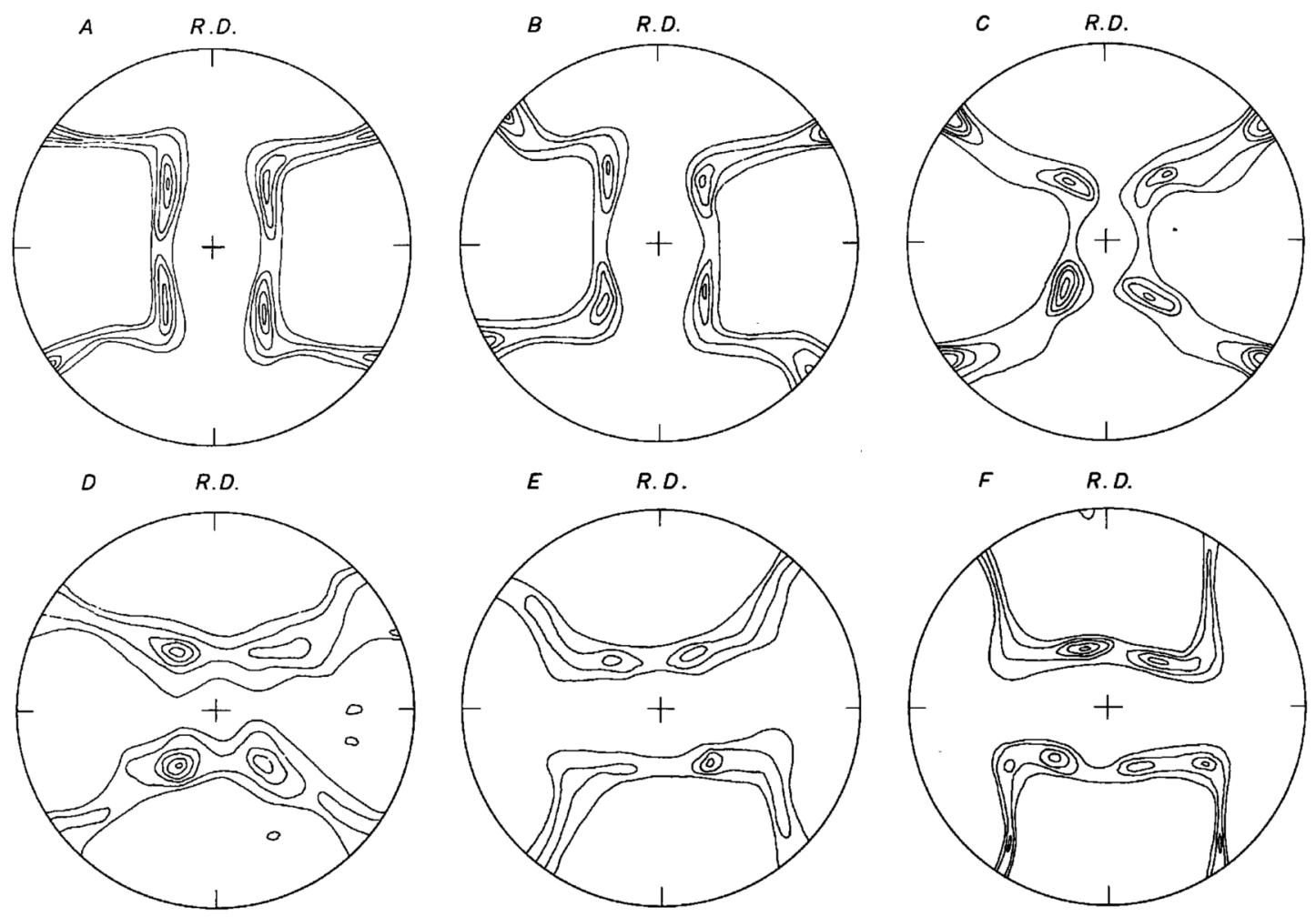

(a) Rolling Texture
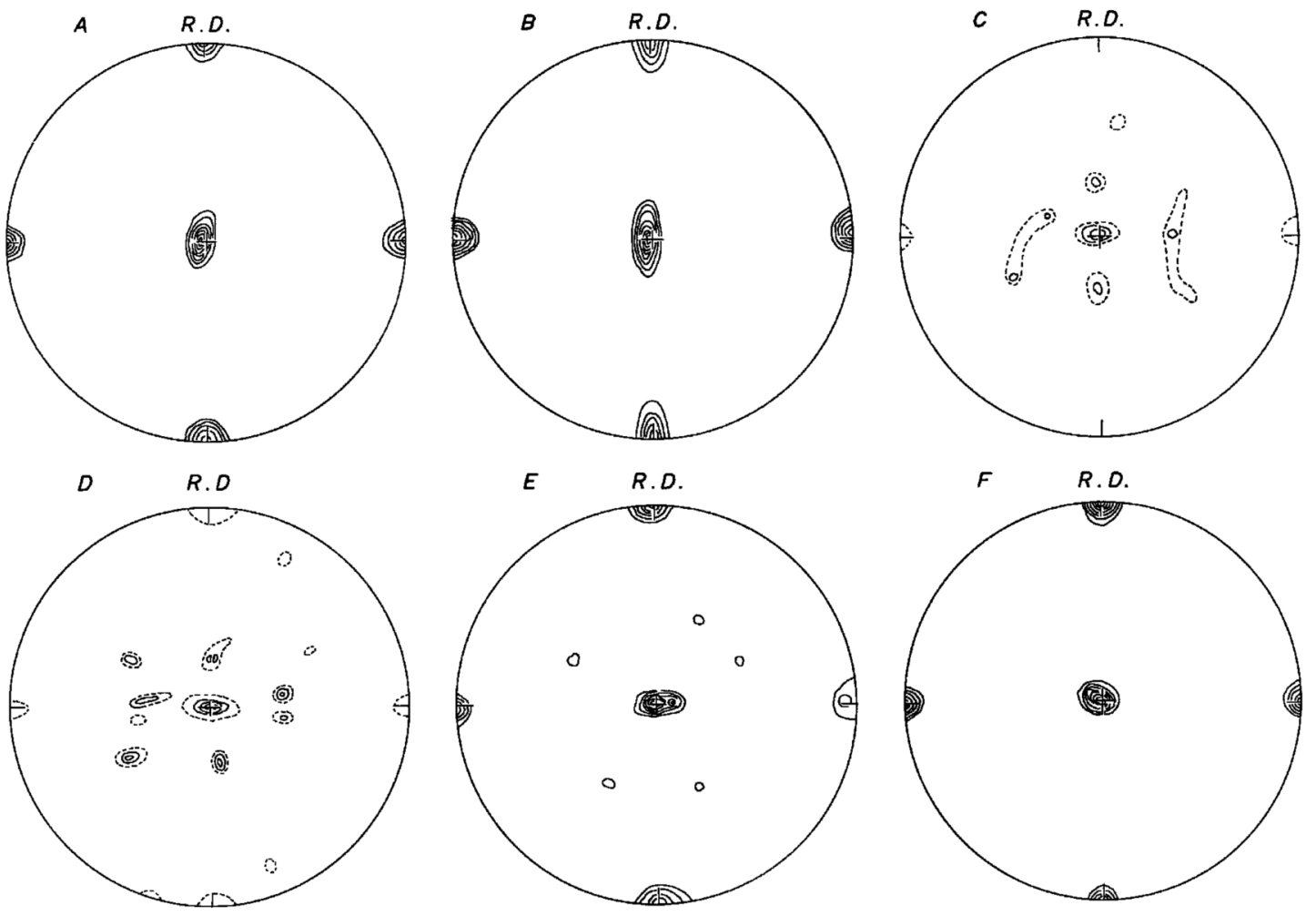

(b) Recrystallization Texture

Fig. 1100 pole figures of the specimens (a) rolled and (b) annealed. R.D. means secondary rolling direction.
A: $94.5 \%+9 \%$
B: $93.8 \%+20 \%$
C: $90 \%+50 \%$
D: $87.5 \%+60 \%$
E: $80 \%+75 \%$
F: $50 \%+90 \%$ 


\section{Texture change in secondary rolling}

The cold rolled textures and the recrystallization textures were investigated by the measurement of 100-pole figures. They are shown in Fig. 1(a) and (b). Without secondary rolling, 95\% rolled copper recrystallized into a well-developed cube texture, and this component decreased with increasing secondary reductions $(\sim$ several tens of $\%)$. Further increase in secondary reductions increased again the cube component in the recrystallization texture. There could be seen little difference in the texture of the as-rolled and annealed specimens secondly rolled less than $20 \%$, except for the appearance of the intensity at the periphery regions of the pole figure for the specimen secondly rolled by $20 \%$. Here the texture formed by the primary rolling and the texture developed after the secondary rolling are termed the primary texture and the secondary texture, respectively. On smaller secondary rolling reductions, the primary textures of the as-rolled and the annealed specimens slightly increased the spread of the major components. The rolling textures of the specimens (secondly rolled by 50 to $60 \%$ ) rotated around the plane normal (P.N.) by $90^{\circ}$ were similar to the brass-type texture in the same way as observed for the recrystallization textures. At the same time, a weak cube component was seen at the center of the pole figures. Further increase in secondary rolling reductions makes the rolling texture similar to the primary texture rotated around P.N. by $90^{\circ}$; also the cube texture developed completely. The trend observed in this experiment was that the primary textures were easily collapsed by a relatively small degree of secondary rolling (lower than $20-30 \%$ ). Whereas, the development of the secondary texture was gradual. The 200-reflective intensity at the center of the pole figure is shown in Fig. 2 as a function of secondary rolling reduction. The optical microscopic observation showed that grains in which the (100) plane appeared on the specimen surface were all in the cube orientation. Thus, the intensity of the reflection could be regarded as the corresponding the amount of the cube component present.

\section{Differential calorimetric analysis}

In general the differential calorimetric measurement

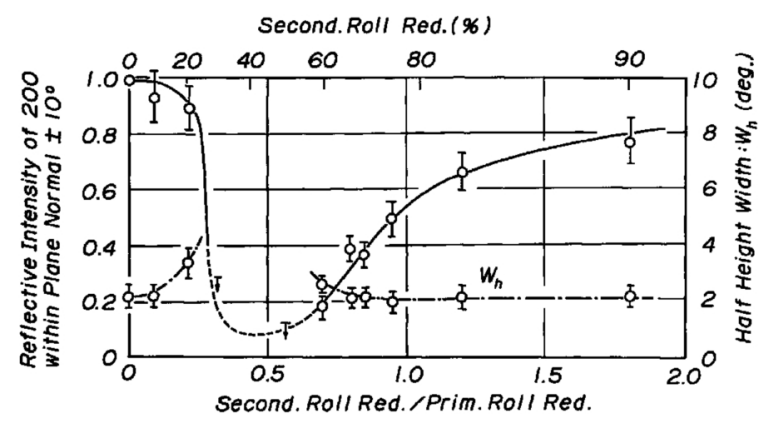

Fig. 2200 reflective intensity at the central portion of the pole figure (N.D. \pm 10 deg.) and the half height width versus secondary rolling reduction. is not carried out under thermally non-equilibrated conditions. Further, owing to the fact that the recovery and the recrystallization process depend upon heating rates, the analysis is made more complicate. In this experiment, a heating rate of $3.2^{\circ} \mathrm{C} / \mathrm{min}$ was employed. The measured calorimetric curves are shown in Fig. 3, which may be considered as semi-quantitative ones. These curves appear to correspond to the recrystallization process, because the energy release during the recovery stages less contributes to these curves. This is confirmed by the fact that the heat evolution is not observed until the recrystallized grains are found by the microscopic observation. Also, the microstructural change was scarcely observed by electron microscopy in the first half stage of the primary recrystallization process. Therefore, in this work, the amount of the heat evolution was considered as the value corresponding to the recrystallized volume.

Provided the release rate of the stored energy $d E / d t$ is proportinal to the residual stored energy $E_{s}$,

$$
d E / d t \propto E_{s} \exp (-Q / R T)
$$

and

$$
E_{s}=E_{t}(1-q)(1-w)
$$

where $Q$ is the apparent activation energy for recrystallization, $q$ is the volume fraction recrystallized, $E_{t}$ is the total stored energy and $w$ is the recovery term (neglected in this work for the reason mentioned above). Then,

$$
d E / d t=C(1-q) \exp (-Q / R T)
$$

where $C$ is the constant and $d E / d t$ is directly measured by the power difference of the differential calorimeter. The above equation is the same as that proposed by Cook and Richards ${ }^{(12)}$.

According to the equation, the differential calorimetric curves of the early stages were well plotted on a linear line, however, after the peak of the curve spread widely; then the linearity was broken down. This equation might be valid for the stages of smaller fraction recrystallized.

The energy release by the grain growth at the expense of the deformed matrix containing high density dislocations may be much larger than that released from the matrix region in the recovery pro-

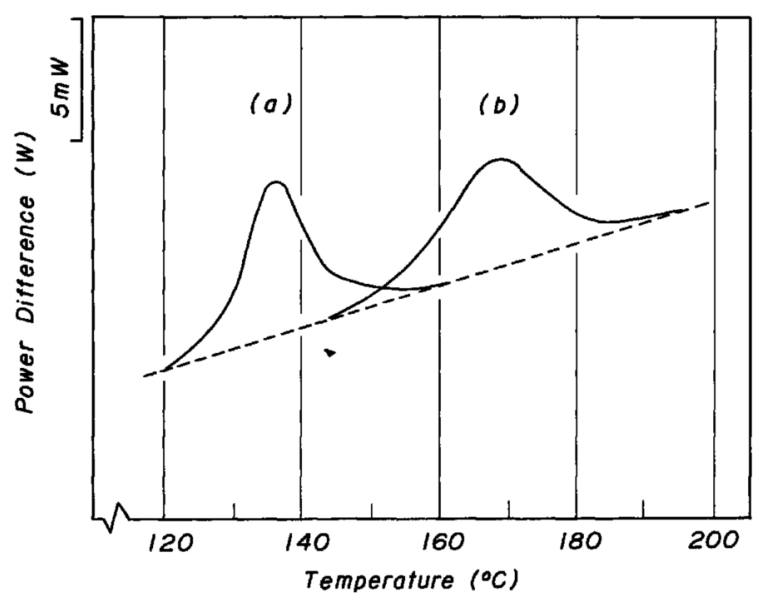

Fig. 3 Differential calorimetric curves of the specimens cold rolled (a) $95 \%$ and (b) $90 \%+50 \%$. 
cess. The microstructural change of the deformed matrix in the heavily cold-rolled $\mathrm{Cu}$ is small until the impingement of the recrystallized grains occurs. The recrystallization behavior may be less affected by the recovery process even if the microstructural change of the deformed matrix takes place, because this process is mainly composed of the gradual decrease in
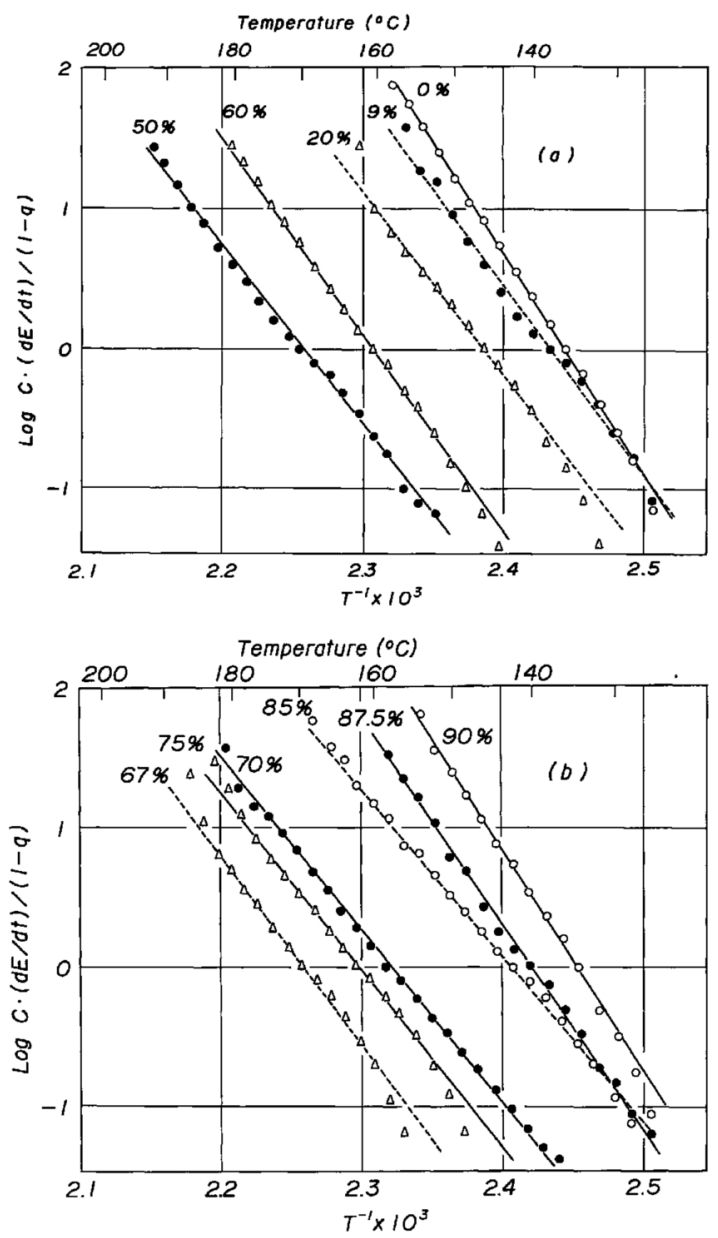

Fig. 4 Arrhenius plots of the differential calorimetric curves. The parameters are secondary rolling reductions $(\%)$.

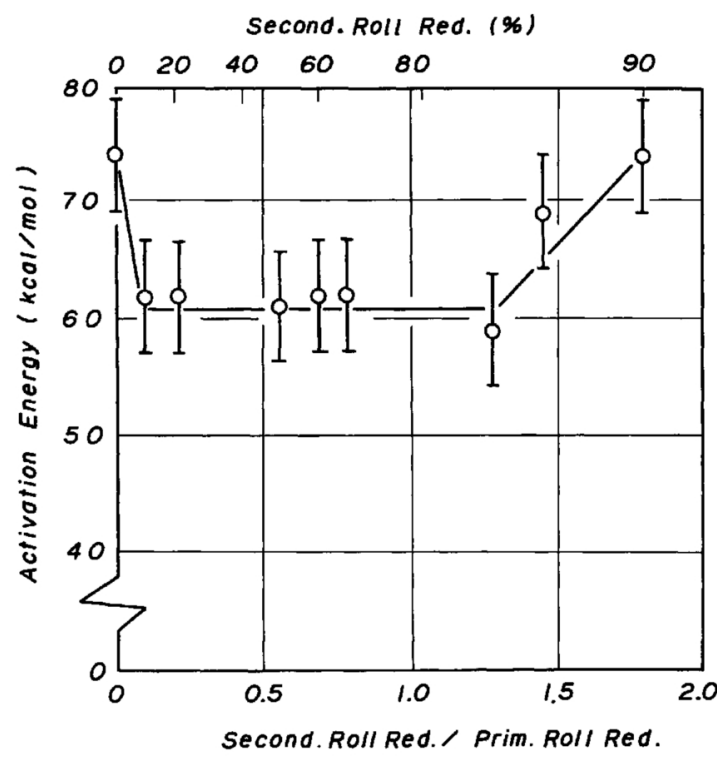

Fig. 5 Activation energy as a function of secondary reduction. the dislocation density. Thus, it may be possible to assume that the recrystallization kinetics does not change up to this stage, and also that the activation energy is invariable for this process.

In the present work, the following method was employed. For the stages with a large fraction of the recrystallized volume, the fraction recrystallized was converted into the one unrecrystallized in the equation; i.e. the unrecrystallized volume was considered to increase with decreasing temperature. Then, the plotting was made "inversely" against the temperature from high to low. The plots obtained by this procedure was folded at the peak position of the differential calorimetric curves and then connected to the plots obtained by the normal calculation. As seen in Fig. 4, the plots obtained well lie on a straight line, the above assumption might be reasonable in this experiment.

The activation energies obtained from these plots are shown in Fig. 5. In this figure, the activation energies are nearly the same at 72 and $74 \mathrm{kcal} / \mathrm{mol}$ for the specimen secondly rolled by $90 \%$ and that for the specimen rolled without secondary rolling, respectively. Between these two conditions they are an almost constant value of $62 \mathrm{kcal} / \mathrm{mol}$. It should be noted that the activation energies decreased only by $9 \%$ reduction of secondary rolling. For secondary reductions larger than $80 \%$, they increased gradually with increasing reductions. These values are somewhat larger than 50 and $53 \mathrm{kcal} / \mathrm{mol}$ obtained by Mengelberg et al. ${ }^{(13)}$ and Haessner and Holzer ${ }^{(14)}$, for heavily deformed high purity $\mathrm{Cu}$, respectively.

\section{Discussion}

On the formation of the cube texture will be discussed here. The recrystallization textures of the specimens rolled without secondary rolling and with large secondary reductions more than $90 \%$ (in which a fairly developed secondary rolling texture was obtained) were both well-developed cube textures and their activation energies were nearly equivalent. On relatively small secondary reductions $(\sim 20 \%)$, the activation energy changed more rapidly than the change in the amount of the cube component and the energy values of the specimens were the same as those of the specimens secondly rolled by moderate reductions, in which the cube component developed to a small extent. It seems likely that in spite of the negligibly small difference of the cube component, the growth mechanism of the cube grain was somewhat different in both cases. Provided the cube grain grows from its component, the cube texture formation might not be affected directly by the secondary rolling because of the symmetry of this component. The structural and orientational changes of the cube component would take place with those of the matrix adjacent to it. In the case of small secondary reductions, the rolling and recrystallization textures changed little, and therefore it was presumed that the balance among the main texture components was reserved in both cases. The abrupt change in the activation energy 
might be due to the configurational change occurring at the boundary region between the cube component and the matrix, or the structural change as in the dislocation structures (not the orientation relationships among each component). However, the latter case may be less responsible for the phenomena because the slight rolling is applied to the specimens preliminarily rolled by very high reductions.

Therefore, it seems reasonable to consider that the effect of the secondary rolling is localized at the weak components in the rolled materials. The cube component, which plays an important role in the recrystallization process, is one of these components. This cube component tends to remain in the rolled materials due to the symmetric slip systems.

For the two reasons mentioned above, the boundary region between the cube component and the deformed matrix will be very sensitive to the effect of the secondary reductions. Thus, even a slight degree of secondary rolling markedly affects the weak components. Therefore, if the orientational relationship between the recrystallized grains and the rolled matrix does not change, the recrystallization behavior might be determined during the stages of the nucleus formation.

If the cube component retained its preferential growth up to the impingement of the recrystallized grains, the well-developed cube texture will be expected as shown in Fig. 1(b). On the other hand, the condition for the cube texture formation by "intrinsic" growth of the component (as in the case of the rolling without secondary reductions) would be a very critical one; thus the slight departure from the conditions, i.e. the smaller addition of the secondary reductions, probably caused the cube component to grow by the same mechanism as in the case of other grains.

With increasing secondary reductions, the rolling texture would approach the critical condition according to the assumption discussed above. This condition and the "proper" activation energy for the growth of the cube grain might be achieved by a rather gradual process due to the secondary texture formation. Once the nucleus or the initial recrystallized grain was formed, the growth behavior of the grains larger than the critical size would not be influenced by the orientation of the deformed matrix. On the contrary, according to the oriented growth mechanism ${ }^{(15)}$, the growth is mainly controlled by the orientation relationships between the growing grains and the matrix. In other words, if the recrystallization texture is formed by the growth after the random nucleation, the grain growth mechanism of the recrystallized grains and the activation energy for the recrystallization process will not change as long as the orientational relationships among the deformed texture components do not change.

\section{Conclusions}

The recrystallization process of the cold rolled $\mathrm{Cu}$ sheets, rolled by $95 \%$ by various rolling processes, was studied by the differential calorimeter, the texture measurement by X-ray diffraction, and microscopic observations. The results obtained are as follows:

(1) The rolling texture of the specimens secondly rolled by $90 \%$ was the same as the texture rotated around N.D. by $90^{\circ}$ in the specimen rolled without secondary rolling procedures. The recrystallization texture and the activation energy was nearly the same in both cases.

(2) At relatively small reductions of secondary rolling, the activation energy decreased to its value for the specimens secondly rolled by moderate reductions ( $\sim$ several ten $\%$ ).

(3) It is very likely that the condition for the "intrinsic" growth of the cube grain is easily collapsed and is achieved by a rather gradual process.

(4) The "intrinsic" growth mechanism of the cube grain might be determined during the stages of the nucleus formation or the initial growth of the cube grain. The predominance of the cube grain growth presumably originated from the configuration of the boundary regions between the cube component and the matrix in the deformed materials.

\section{Acknowledgment}

The authors wish to thank Mr. M. Ueda of Fuji Photo Film Co. for his cooperation during this work.

\section{REFERENCES}

(1) For example, C. S. Barrett and T. B. Massalski: Structure of Metals, 3rd ed. McGrow Hill, New York, (1966); G. Wassermann und J. Grewen: Texturen Metallischer Werkstoffe, Springer, Berline, (1962); V. Guttmann: Z. Metallk., 64 (1973), 94.

(2) W. F. Johnson and R. F. Mehl: Trans. AIME, 135 (1939), 416.

(3) M. Avrami: J. Chem. Phys., 7 (1939), 1103.

(4) J. E. Burke and D. Turnbull: Progress in Metal Phys., III, Pergamon Press, New York, (1952), p. 220.

(5) R. A. Vandermeer and P. Gordon: Recovery and Recrystallization in Metals, L. Himmel ed., Interscience Publishers, New York, (1963), p. 211.

(6) A. Van Den Beukel: Acta Met., 11 (1963). 97.

(7) R. O. Williams: Acta Met., 9 (1961), 949.

(8) H. Steffen, G. Gottstein and H. Wollenberger: Acta Met., 21 (1973), 683.

(9) A. Wolfenden: Acta Met., 15 (1967), 971.

(10) H. G. Grewe, P. F. Schmidt und K. Schur: Z. Metallk., 64 (1973), 502.

(11) H. Nakae and A. Okada: Trans. JIM, 10 (1969), 85.

(12) M. Cook and T. L. Richards: J. Inst. Metals, 49 (1946), 1.

(13) H. D. Mengelberg, M. Meixner and K. Lücke: Acta Met., 13 (1965), 845.

(14) F. Haessner and H. P. Holzer: Scripta Met., 4 (1970), 161.

(15) P. A. Beck: Phil. Mag., Suppl., vol. 3 (1954), 245. 